the concentrations of naturally occurring isotopes are of great potential importance in determining the size and recharge of ground-water reservoirs. Tritium is the main isotope used in this connexion, but present research is considering the use of carbon isotopes. Two papers are concerned with investigations using the latter isotopes, and in the paper by Munnich and Roether, simultaneous measurements wore made of both tritium and carbon-14 in the same sample.

The third main field in which the use of radioartive isotopes is at present being explored is in the movements of water-borne sediments. The application is a simple one when used qualitatively and will show the direction as well as some measure of the speed of sediment movement, but meets with considerable difficulties in attempting quantitative measurements. Three papers describe experiments designed to measure sediment movements, two in rivers and the third marine. The general principle behind most of these methods is equivalent to that in the measurement of liquid discharge, and the technique includes the incorporation within the sediment of suitably labelled particles. Lean and Crickmore used glass particles in which a small percentage of scandium is included. Another application in the field of sediment movement is described in a paper by Ariizumi and Kondo, who used a gamma-ray densimeter suspended in a tube driven into the bed of a river by which the boundary face between the water and the river bed was determined and whereby information could be obtained on the variations of the river bed during flood.

The Proceedings of this symposium well illustrate the wide field of possible applications of radioisotopes techniques and, in view of the present emphasis on hydrological investigations, a rapid development is to be expected in their use. It is of particular value, therefore, that these twenty-seven papers which might normally have been distributed in several different journals should be aggregated in a single collection.

F. WRIGHT

\section{PROTEINS IN MEDICINE}

\section{Dysproteinämien und Paraproteinämien}

Grundlagen, Klinik und Therapie. Von Prof. Dr. med. Ferdinand Wuhrmann und Dr. med. Hans Heinrich Märki. Pp. 851. (Basle und Stuttgart: Verlag Schwabe and Co., 1963.) n.p.

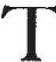
HIS fourth edition of Die Bluteiweisskörper des Menschen has changed its title, its co-author and a great deal of the text, hence it ought to be treated as a completely new publication. As such it deserves careful study and, in my opinion, it is well worth the effort, whether the reader be engaged in laboratory work or in the clinical management of patients.

Two hundred of the 772 pages of text are devoted to basic physiology and chemistry of the proteins. This essential knowledge has been admirably presented; the style is lucid and the diagrams are helpful-were it not for the language barrier one would strongly recommend this text to final-year medical students.

Not quite so much praise can be given to the section on analytical methods; the presentation here is uneven. For example the copper sulphate specific gravity method for total protein determination is not mentioned, quantitative 'salting-out' techniques are not discussed, neither are nephthelometric nor spectrophotometric techniques described which have been used for special procedures in quantitative protein assay work. On the other hand, prominence is given to the non-specific flocculation techniques, a dozen of which are described in detail; the latest addition here being the 'reticulo-endothelial index' of Sandor.

Paper electrophoresis is described in detail, but no mention is made of cellulose acetate as a supporting medium. Immuno-electrophoresis in agar gel is fully described and the interpretation of the results of this relatively new technique is carefully reviewed in the clinical section. Some of the illustrations, however, seem repetitive, yet others like urine and cerebro-spinal fluid immuno-electrophoretic patterns are regrettably absent.

The main part of the book deals with the vast field of protein disorders and cannot be reviewed here in detail. It is admirable for its clarity of thought and expression, though some of us would quarrel with the over-zealous drive at classification. A chapter on treatment is a new venture in this edition, and show's more clearly than any other the gulf that oxists between British and Continental medicine. This is to be found not so much in a diversity of therapeutic agents but rather in the reasons for which they are used.

These minor eriticisms do not detract from the value of the book as a whole. It is a welcome addition to the clinical literature and should appear in translation. The publishers are to be congratulated on a most attractive and faultless production.

E. KAWERAT

\section{INDUSTRIAL PLASTICIZERS}

\section{Industrial Plasticisers}

By Ibert Mellan. Pp. ix +302 . (London and New York: Pergamon Press, 1963.) 70s, net.

THERE is a need for an authoritative British book on plasticizers. in that there have been considerable developments in this field since the publication of Doolittle's work ten years ago. Jr. Mellan's book is a dis. appointing answer to this challenge. It provides a largely uncritical collection of the semi-technical data available from American plasticizer manufacturers, and tables describing the behaviour of plasticizers with the major resins and polymers, which have already been published elsewhere, are collectively reproduced in this volume.

The book is rather unattractive in its layout. There is no preface, and the groups of plasticizers are arranged in alphabetical order, with no chapter headings, and frequently no general discussion on the class as a whole. This results in adipates and sebacates appearing in different sections of the book, with no indication that these materials have similar properties and applications. Even the alphabetical order is not strictly adhered to, since phthalates precede phosphates, and towards the end of the book all semblance of order disappears. It is surprising that the author devotes 8-9 pages of text to nitrocellulose, while giving only a little more than a page to polyvinylchloride/polyvinylacetate co-polymers and nothing at all to straight polyvinylchloride polymer.

Only those materials manufactured in the United States are mentioned; this is perhaps understandable, but it is surprising that there is not a single reference to any work published outside the United States. The information given on each individual plasticizer is rather typical of that shown in manufacturers' technical literature, in giving too wide a range of uses, and not always clearly indicating where the major uses lie and for what reasons. It also suffers from the inevitable disadvantage that the physical properties given are not all in comparable units, and boiling points of different materials are frequently given at different pressures.

Since a number of new products have appeared in the past ten years, this book is of value, since it does form an up-to-date and useful collection of data on the plasticizers at present available in the United States, which are substantially the same as those available in Britain, together with a useful collection of recently published American work. Thus, in spite of its shortcomings, it will probably find its way into the libraries of most worker's interested in this field as an up-to-date list of plasticizers available in the United States. $\quad$ R. J. W ICKER 